Selkon, J. B. \& Mitchison, D. A. (1957). J. gen. Microbiol. 16, 229-235

\title{
Viable Counting of Mycobacterium tuberculosis in a Silica Gel Medium
}

\author{
By J. B. SELKON ANd D. A. MITCHISON \\ Medical Research Council Group for Research into Drug Sensitivity in Tuberculosis, \\ Postgraduate Medical School of London, London, W. 12
}

SUMMARY: A method is described in which deep counts of Mycobacterium tuberculosis are made in a defined medium solidified with silica gel. The method was accurate, simple and safe. The contamination rate was low. Deep counts were higher than surface counts on plates. The defined medium was superior to Kirschner medium.

The enumeration of viable bacteria is most frequently and accurately carried out on the surface or in the depths of solid medium. A surface viable count method for Mycobacterium tuberculosis using oleic acid + albumin agar medium was described and statistically analysed by Fenner (1951). Yegian \& Budd (1951) also described a pour plate technique for mycobacteria using the same medium and they suggested that it yielded a higher count than the former method. A disadvantage of the surface count technique is the high rate of contamination, which in our hands has occasionally been as high as $15 \%$ of the plates inoculated. In order to avoid contamination Mitchison (1950) and O'Hea (1955) described surface count methods in which the medium was distributed into small bottles and each of these was inoculated with a drop of the appropriate culture dilution. These methods are inconvenient where accurate work is required because of the large number of bottles used. Hirsch (1954) pointed out that agar has an inhibitory action on the growth of tubercle bacilli, only in part due to binding of the ferric ion. Knox (1955) described a technique for deep counts in a semi-solid medium of low agar concentration, contained in tubes. In this method optimal conditions for growth varied according to the depth of the colonies in the column of the medium and this may possibly be a source of error. Knox has not published accounts of comparisons with Fenner's method. We have investigated the use of a deep culture medium solidified with silica gel in place of agar. The counts can then be set up in narrow-necked bottles which decreases the incidence of contamination and allows the formation of a thin well-aerated layer of medium.

\section{METHODS}

Organisms. Mycobacterium tuberculosis; strains $\mathrm{H37Rv}$ and H37Ra, obtained from Dr R. J. W. Rees (Medical Research Council Laboratories, Mill Hill, London); Branch, a bovine strain, obtained from Dr A. Q. Wells (Sir William Dunn School of Pathology, Oxford); strain B.C.G., Copenhagen strain, obtained from current batches of vaccine; strain $B$, a variant of $\mathbf{H 3 7} \mathbf{R v}$ highly resistant to isoniazid and catalase-negative (Barnett, Bushby \& Mitchison, 1953); strains 0139 and 0704, recently isolated from patients with 
pulmonary tuberculosis and sensitive to streptomycin, $p$-aminosalicylic acid (PAS) and isoniazid; strains 0942 and 0435 , human strains recently isolated from patients with pulmonary tuberculosis and resistant to PAS but sensitive to streptomycin and isoniazid.

Media. Unless otherwise stated, the medium used was the $7 \mathrm{H}-3$ medium described by Middlebrook, Cohn \& Schaefer (1954). Since a multiplicity of media was described by these authors, the method of preparation is given:

Basal medium. $\mathrm{KH}_{2} \mathrm{PO}_{4}, 0 \cdot 2$ g.; $\mathrm{Na}_{2} \mathrm{HPO}_{4} .12 \mathrm{H}_{2} \mathrm{O}, 1 \cdot 26$ g.; sodium-L-glutamate, 0.1 g.; $\left(\mathrm{NH}_{4}\right)_{2} \mathrm{SO}_{4}, 0.1$ g.; sodium citrate. $2 \mathrm{H}_{2} \mathrm{O}, 0.02$ g.; $\mathrm{MgSO}_{4} .7 \mathrm{H}_{2} \mathrm{O}$, $0.01 \mathrm{~g}$.; $\mathrm{CaCl}_{2} .2 \mathrm{H}_{2} \mathrm{O}, 0.0001 \mathrm{~g}$; $\mathrm{ZnSO}_{4} .7 \mathrm{H}_{2} \mathrm{O}, 0.0002 \mathrm{~g}$; $\mathrm{CuSO}_{4} .5 \mathrm{H}_{2} \mathrm{O}$, $0.0002 \mathrm{~g}$; ; pyridoxine hydrochloride, $0.0002 \mathrm{~g}$; biotin, $0.0001 \mathrm{~g}$.; glycerol, $0.4 \mathrm{ml}$.; ferrous ammonium citrate, $0.02 \mathrm{~g}$.; distilled water to $100 \mathrm{ml}$. Adjust $\mathrm{pH}$ to $\mathbf{7 \cdot 2}$ with $\mathrm{HCl}$. Autoclave at $15 \mathrm{lb}$./sq.in. $\left(120^{\circ}\right)$ for $20 \mathrm{~min}$.

Oleic acid-albumin complex. (a) Bovine Albumin Fraction V (Armour) $10 \mathrm{~g}$.; glucose, $4 \mathrm{~g}$. Dissolve in $0 \cdot 85 \%$ saline to $190 \mathrm{ml}$. (b) Oleic acid, $0.12 \mathrm{ml}$; $0.05 \mathrm{~N}-\mathrm{NaOH}, 10 \mathrm{ml}$. Mix $(a)$ and $(b)$. Seitz filter and add $20 \mathrm{ml}$. to $100 \mathrm{ml}$. of basal medium. For plates solidified with agar the $7 \mathbf{H}-3$ basal medium was diluted with $100 \mathrm{ml}$. distilled water. Malachite green to a final concentration of $0.0001 \%$ and agar to $1.4 \%$ were added. The medium was autoclaved (15 lb./sq.in. for $20 \mathrm{~min}$.) and then $20 \mathrm{ml}$. of the oleic acid albumin complex added.

A liquid medium modification of the $7 \mathrm{H}-\mathbf{3}$ medium was also used, in which glycerol was omitted from the basal medium and $100 \mathrm{ml}$. water, $0.025 \%$ Tween 80 (Atlas Powder Co.), $0.2 \%$ glucose and $0.5 \%$ bovine albumin were added.

Kirschner Medium (Mackie \& McCartney, 1953) was used in one experiment with the following modifications. Penicillin was not added to the horse serum; the $\mathrm{pH}$ of the medium used for agar plates was adjusted 6.7 with $\mathrm{N}-\mathrm{HCl}$; the medium used with the silica sol was prepared at double concentration and its $\mathrm{pH}$ was adjusted to $7 \cdot 2$ with $\mathrm{N}-\mathrm{HCl}$.

Silica sol. A $2 \cdot 6 \%$ sol was prepared according to the method described by Smith (1951), using Zeo-Karb 225 (Permutit Co. Ltd., London, W.4) as the cation-exchange resin. The sol was sterilized by autoclaving at $15 \mathrm{lb}$./sq.in. for $15 \mathrm{~min}$. and was stored in $c .100 \mathrm{ml}$. volumes in Pyrex flasks at $4^{\circ}$. It remained usable for at least a week.

Diluent. Sterile distilled water or $0.1 \%$ bovine albumin fraction $\mathrm{V}$ in distilled water were used in different experiments.

\section{Use of silica gel solidified medium}

The medium to be solidified with silica gel was distributed with aseptic precautions in $3 \mathrm{ml}$. amounts into $2 \mathrm{oz}$. sterile medical flats with screwcaps. The bottles were incubated at $37^{\circ}$ for 2 days as a sterility check and then could be stored, when necessary, for several months at $4^{\circ}$. Dilutions of cultures or of tissue homogenates were then added, usually in $0.2 \mathrm{ml}$. volumes from $1 \mathrm{ml}$. graduated pipettes. These operations were carried out inside an inoculation hood using a Pumpett automatic pipette control (Shandon, 
London). Accurate counts were obtained using $\mathbf{4 0}$-fold dilution steps. After inoculation of all the bottles on any day, $3.2 \mathrm{ml}$. of the silica sol were added to each, the contents were mixed and the bottles immediately laid flat on the bench, so that a layer of medium about $3 \mathrm{~mm}$. deep covered one of the larger surfaces. Gelling began within $5 \mathrm{~min}$. and was complete after $c .1 \mathrm{hr}$., during which period the bottles were left undisturbed. They were incubated for 4 weeks at $37^{\circ}$ and colonies were then counted as in pour plates. When the number of colonies was between 600 and 2000 /bottle an approximate count could be obtained by counting within a series of thin-ruled areas at intervals along the bottle. Less accurate counts up to $10^{5}$ colonies/bottle could even be made with a plate microscope containing a square of known area in the eye-piece focal plane.

For surface counts on plates the method of Fenner (1951) was used. Dropping pipettes were calibrated both with a micrometer screw gauge and by measuring the volume of a large number of drops. Counts were made after 4 weeks of incubation.

\section{RESULTS}

\section{Comparison of deep and surface counts}

In the first experiment (Table 1) 10-day cultures of strains grown in $7 \mathrm{H}-3+$ Tween + albumin medium were diluted $1 / 10^{5}$ in sterile distilled water and this dilution was inoculated on to plates and into bottles. The counts on

Table 1. Surface and deep viable counts of Mycobacterium tuberculosis using $7 \mathrm{H}-3$ medium

$\chi^{2}$ tests the conformance of the counts on the strains H37 Rv, H37 Ra, Branch and B.C.G. to a Poisson distribution.

\begin{tabular}{|c|c|c|c|c|c|c|}
\hline \multirow[b]{2}{*}{ Strain } & \multicolumn{3}{|c|}{ Surface plate counts } & \multicolumn{3}{|c|}{ Silica gel deep counts } \\
\hline & $\begin{array}{l}\text { No. of } \\
\text { replicate } \\
\text { drops }\end{array}$ & $\begin{array}{l}\text { Mean } \\
\text { count/ } \\
\text { drop }\end{array}$ & $\begin{array}{c}\text { Viable } \\
\text { units/ml. }\end{array}$ & $\begin{array}{l}\text { No. of } \\
\text { replicate } \\
\text { bottles }\end{array}$ & $\begin{array}{l}\text { Mean } \\
\text { count } / \\
\text { bottle }\end{array}$ & $\begin{array}{c}\text { Viable } \\
\text { units/ml. }\end{array}$ \\
\hline Ha7 Rv & 6 & $13 \cdot 3$ & $6.67 \times 10^{7}$ & $\mathbf{5}$ & 141 & $7 \cdot 05 \times 10^{7}$ \\
\hline H37 Ra & 9 & $6 \cdot 3$ & $3 \cdot 17 \times 10^{7}$ & 4 & 65 & $3.25 \times 10^{7}$ \\
\hline Branch & 6 & $31 \cdot 3$ & $1.57 \times 10^{8}$ & 4 & $\mathbf{3 4 3}$ & $1.71 \times 10^{8}$ \\
\hline B.C.G. & 18 & $\mathbf{3} \cdot \mathbf{1 7}$ & $1.58 \times 10^{7}$ & 5 & 481 & $2.41 \times 10^{7}$ \\
\hline 0139 & 10 & $29 \cdot 9$ & $1.50 \times 10^{8}$ & $\mathbf{5}$ & 32 & $1.60 \times 10^{7}$ \\
\hline $\mathbf{B}$ & 10 & $2 \cdot 4$ & $1.20 \times 10^{7}$ & 5 & 1 & $5.00 \times 10^{5}$ \\
\hline & \multicolumn{3}{|c|}{$\begin{array}{l}\chi^{2}=43 \cdot 01, \text { D.F. }=35 \\
P=0.5-0.3\end{array}$} & \multicolumn{3}{|c|}{$\begin{array}{l}\chi^{2}=11 \cdot 98, \text { D.F. }=14 \\
P=0.7-0 \cdot 5\end{array}$} \\
\hline
\end{tabular}

silica gel media of strains $\mathrm{H37} \mathbf{R v}, \mathrm{H37} \mathrm{Ra}$, Branch and B.C.G. were slightly higher than the surface plate counts. The $\chi^{2}$ indicates, in both methods, that the scatter of the individual counts followed a Poisson distribution. However, with strains 0139 and $B$, the silica gel counts were far lower than the surface plate counts. Growth of these two strains on both types of media was extremely poor, the colonies being minute even after 4 weeks of incubation. This finding suggested that they were particularly exacting in their growth requirements. 
Cohn, Oda, Kovitz \& Middlebrook (1954) showed that occasional strains of Mycobacterium tuberculosis are very exacting in their nutritional requirements and that isoniazid-resistant strains require a high iron content, pyruvic acid or catalase for their growth. The effect of adding silica sol on the iron concentration and the $\mathrm{pH}$ value of the medium was therefore examined. The addition of the sol, which had a $\mathrm{pH}$ value of 3.02, decreased the $\mathrm{pH}$ value of the medium

Table 2. Surface and deep viable counts using $7 \mathrm{H}-3$ and Kirschner medium

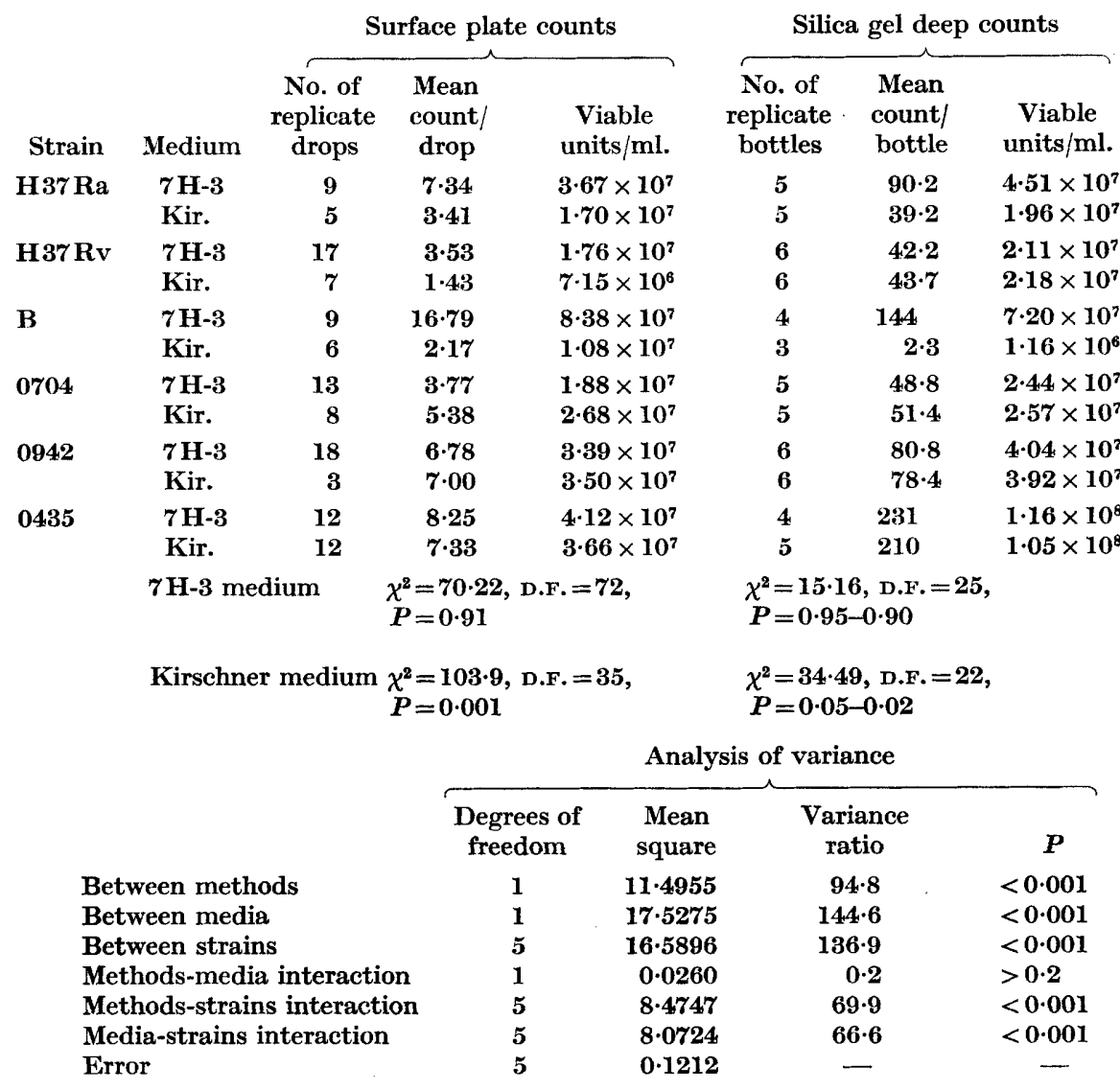

from $7 \cdot 25$ to $6 \cdot 83$ and removed by adsorption approximately half of the ferrous ions. In a second experiment the ferrous ammonium citrate concentration was therefore increased to $0.05 \%$ and the $\mathrm{pH}$ value of the medium used for the plates adjusted to $6 \cdot 8$ by the addition of $\mathrm{N}-\mathrm{HCl}$. In this experiment Kirschner medium and $7 \mathbf{H}-3$ medium were compared, both as plates solidified with agar and as silica gel deep cultures. The results together with an analysis of variance are shown in Table 2 . The $\chi^{2}$ on the counts in $7 \mathbf{H}-3$ medium indicated conformity with a Poisson distribution, but those in Kirschner medium failed to conform. Counts by the silica gel method were significantly 
higher than those on plates and they were also significantly higher in $7 \mathbf{H}$-3 medium than in Kirschner medium. The highly significant interactions between methods and strains, and between media and strains indicates that the differences between the counts by the two methods and in the two media depended on the choice of strain. Strain B grew very poorly both on plates and in deep cultures of Kirschner medium. The analysis of variance was therefore repeated with the omission of the results using this strain, but the same terms were still significant.

\section{Effect of diluent}

The use of distilled water as a diluent was investigated by carrying out viable counts on a $1 / 10^{5}$ dilution of 10-day cultures grown in $7 \mathrm{H}-3+$ Tween + albumin liquid medium, with distilled water or $0 \cdot 1 \%$ bovine albumin as diluents. The results of one of these experiments, with the $H 37 \mathbf{R v}$ strain, is shown in Table 3. There was no decrease in the count over a $24 \mathrm{hr}$. period. A second experiment with strain B yielded similar results. One can therefore conclude that the results of the first two experiments were not influenced by the use of distilled water as a diluent, particularly as counts were always set up within 15 min. of dilution.

Table 3. Viable counts on strain $\boldsymbol{H} 37 \mathrm{R} v$ after contact with distilled water or $\mathbf{0 . 1} \%$ bovine albumin

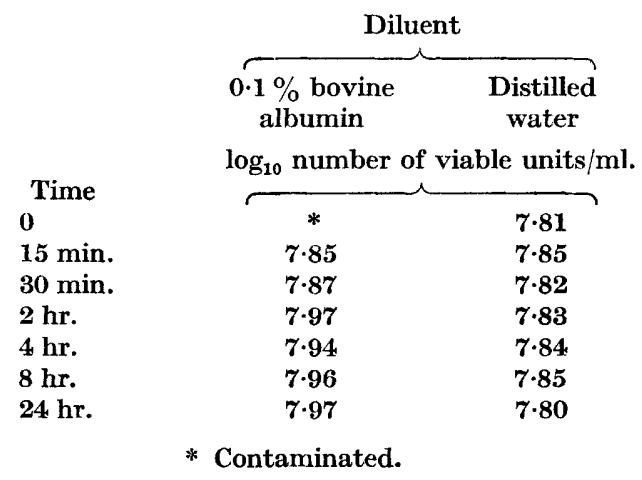

\section{Further use of the silica gel method}

We have used the silica gel method for the past two years in over 3000 counts of cultures and of homogenates of animal tissue. The method has been convenient, accurate and associated with a contamination rate of less than $1 \%$. Comparisons of $7 \mathrm{H}-3$ medium and the oleic acid medium used by Fenner (1951) have shown that counts were the same, within experimental error, but colonies were slightly larger in the $7 \mathrm{H}-3$ medium.

\section{DISCUSSION}

Surface viable counts of Mycobacterium tuberculosis on plates suffer from four disadvantages: (1) The contamination rate is high, particularly in certain laboratories where fungal spores are prevalent. (2) Closely spaced colonies tend to coalesce and are difficult to count. This necessitates the use of closely spaced 
dilution intervals and numerous replicates. Alternatively, counts can be read with a plate microscope when the colonies are small, but the counts then tend to be low. (3) Plates must be poured the day before or the same day as the counts are carried out. (4) The opening of plates to read the counts may be a source of laboratory infections. Contamination is greatly reduced by seeding small bottles of medium with single drops, but the accuracy of this method is diminished by the coalescence of colonies which cannot be differentiated by the use of a plate microscope.

The deep counts of Mycobacterium tuberculosis in silica gel medium have the following advantages. The contamination rate is low, and there is no coalescing of colonies so that accurate counts can be made on bottles containing large numbers of colonies and wide dilution intervals are possible. The medium can be prepared well in advance of its use and the bottles need not be opened for counting. The dilution of drugs or other substances carried over in the inoculum is accurately known. The two disadvantages are that deep colonies have a less characteristic colonial morphology than surface colonies and it is more difficult to subculture from deep colonies. However, these disadvantages are of no great importance in the majority of experiments.

Deep counts in silica gel medium were higher than those on plates. Malachite green was used in the $\mathbf{7 H}$-3 medium plates, but not in the silica gel bottles because it has been recommended as a procedure to decrease contamination. Although it remains possible that this dye may have been responsible for the lower counts, it seems unlikely as Cohn et al. (1954) stated that the concentration used was not inhibitory. Furthermore, phenol red was used in plates and bottles in Kirschner medium and the methods-medium interaction in the analysis of variance in the second experiment was not significant. This suggests that the incorporation of Malachite green in the $7 \mathbf{H}-3$ medium did not contribute to the lower counts on the plates.

Miles \& Misra (1938) found that the $\chi^{2}$ distribution of surface counts was an indication of the quality of the medium. The results of the analysis of variance in Expt. 2 on the size of the counts and the values of $\chi^{2}$ suggest that $7 \mathbf{H}-3$ medium is superior to Kirschner medium.

Although the sterile distilled water used in these experiments had no bactericidal activity over a period of $24 \mathrm{hr}$., this cannot be accepted as a generalization to other laboratories for, as Wilson (1935) has shown, the bactericidal activity of distilled water from different stills varies.

\section{REFERENCES}

Barnett, M., Bushby, S. R. M. \& Mrtchison, D. A. (1953). Tubercle bacilli resistant to isoniazid: virulence and response to treatment with isoniazid in guinea pigs and mice. Brit. J. exp. Path. 34, 568.

Cohn, M. L., Oda, U., Kovitz, C. \& Middlebrook, G. (1954). Studies on isoniazid and tubercle bacilli: 1. The isolation of isoniazid-resistant mutants in vitro. Amer. Rev. Tuberc. 70, 465.

Fenner, F. (1951). The enumeration of viable tubercle bacilli by surface plate counts. Amer. Rev. Tuberc. 64, 353. 
Hirsch, J. G. (1954). Charcoal media for the cultivation of tubercle bacilli. Amer. Rev. Tuberc. 70, 955.

KNox, R. (1955). Semi-solid agar media for rapid culture of tubercle bacilli. Lancet, ii, 110.

Mackie, T. J. \& McCartney, J. E. (1953). Handbook of Practical Bacteriology, 9th ed. p. 189. Edinburgh: Livingstone.

Middlebrook, G., Cohn, M. L. \& Schaefer, W. B. (1954). Studies on isoniazid and tubercle bacilli from isoniazid treated patients. Amer. Rev. Tuberc. 70, 852.

Mrles, A. A. \& Misra, S. S. (1938). The estimation of the bactericidal power of the blood. J. Hyg., Camb. 38, 732.

Mrtchison, D. A. (1950). Development of streptomycin resistant strains of tubercle bacilli in pulmonary tuberculosis. Thorax, 5,144 .

O'Hea, A. J. (1955). Counting viable tubercle bacilli. J. Path. Bact. 69, 169.

Sмrтн, W. K. (1951). Improvements in the ion-exchange method of preparing silica sols. Proc. Soc. appl. Bact. 14, 139.

Wilson, G. S. (1935). The bacteriological grading of milk. Spec. Rep. Ser. med. Res. Coun., Lond. no. 206.

YegiaN, D. \& BUDD, V. (1951). The growth and enumeration of mycobacteria in transparent agar medium. Amer. Rev. Tuberc. 64, 81.

(Received 27 August 1956) 